\title{
Moshebi's Shelter at fifty: Reinvestigating the Later Stone Age of the Sehlabathebe Basin, Lesotho
}

\author{
Peter Mitchella,b, Charles Arthur ${ }^{\mathrm{a}}, \operatorname{Hugo}^{\mathrm{a}}$ into $^{\mathrm{c}}$ and Cristian Capelli ${ }^{\mathrm{d}}$

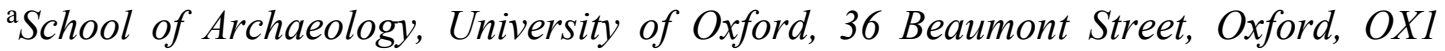 \\ 2PG, United Kingdom \\ ${ }^{\mathrm{b}}$ School of Geography, Archaeology and Environmental Studies, University of the \\ Witwatersrand, PO Wits 2050, Johannesburg, South Africa \\ ${ }^{c}$ Department of Anthropology, University of Toronto Scarborough, 1265 Military \\ Trail, Toronto, Ontario, M1C 1A4, Canada \\ ${ }^{\mathrm{d}}$ Department of Zoology, University of Oxford, New Radcliffe House, Woodstock \\ Road, Oxford, OX2 6GG, United Kingdom
}

\begin{abstract}
Professional archaeology in Lesotho was initiated 50 years ago when Pat Carter, working with Patricia Vinnicombe, excavated the site of Moshebi's Shelter in the Sehlabathebe Basin. His excavations there identified a sequence of both Middle and Later Stone Age (LSA) industries, the latter falling within the last 2200 years. However, the site was never fully published and Carter's use of $10-\mathrm{cm}$-thick spits to excavate its deposits raises questions about the precise stratigraphic provenance of the finds made. As part of renewed investigations into hunter-gatherer/farmer interactions in highland Lesotho, Moshebi's LSA deposits were re-excavated in 2009. This paper summarizes the results of the archaeological sequence recovered, their dating using both radiocarbon and OSL techniques, and their implications for past human use of the site and the wider Maloti-Drakensberg landscape.
\end{abstract}

Keywords: Moshebi's Shelter; Lesotho; Later Stone Age; Holocene; hunter-gatherer archaeology

\section{Introduction}

Moshebi's Shelter was the first rockshelter investigated by professional archaeologists in Lesotho and its excavation in 1969 by Pat Carter (1969a, 1976, 1978; Carter and Vogel 1974) initiated a series of projects that continue to explore the prehistory of hunter-gatherer populations across the wider Maloti-Drakensberg region. We report here on our re-excavation of its Later Stone Age (LSA) deposits as part of broader enquiries into the history of hunter-gatherer/farmer relations in this part of southern Africa. We chose to work at Moshebi's because the stratigraphy and radiocarbon dates that Carter reported (Carter and Vogel, 1974) suggested that it might be particularly well-suited to developing a high-resolution view of the interactions between hunter-gatherers and food-producers over the last 2000 years. Our hope was that this could then serve as a springboard for further work in the region, while complementing genetic studies of contemporary populations in Lesotho.

We excavated at Moshebi's between 29 April and 21 May 2009, expanding the 1969 excavation area eastward by a $2 \mathrm{~m}^{2}$ area that we offset slightly from Carter's trench to accommodate the undercutting of his sections over the intervening forty years. All 
excavated material was passed through a $2 \mathrm{~mm}$-wide mesh. All non-faunal finds were taken to Oxford for analysis in the United Kingdom and are reported here, along with a revision of Moshebi's LSA archaeological sequence within the context of MalotiDrakensberg prehistory as a whole. The associated faunal assemblages have already been published (Badenhorst et al., 2019), as have results of our genetic sampling, which show an unexpectedly high level of San ancestry in the present-day Basotho population and contribute to understanding the expansion of Bantu-speaking groups through southern Africa (Marks et al., 2012, 2015; González-Santos et al., 2015; Montinaro et al., 2016).

It is clear from our re-excavation of Moshebi's that the site's stratigraphy is significantly more complicated than was hitherto appreciated and that this can now be understood to include a succession of spring-induced channels, episodes of pit and posthole construction, and rodent tunnelling. Although this varied depositional history has made it extremely difficult to create the high-resolution sequence for which we had initially hoped, on reflection, the results remain significant. In the first instance, they demonstrate the importance of revisiting sites using contemporary excavation techniques and show how through detailed stratigraphic interpetation and careful analysis of finds it remains possible to understand the depositional history of a rockshelter like Moshebi's. In the second instance, they help us appreciate that, rather than signifying a problem, such processes reflect the reality of 'place'. We show that although chronologically more complicated than we had initially wished for, Moshebi's can nevertheless contribute to uncovering the complex layering of human occupation in the highlands of Lesotho. In that sense, it offers both a cautionary and an encouraging tale.

\section{Background}

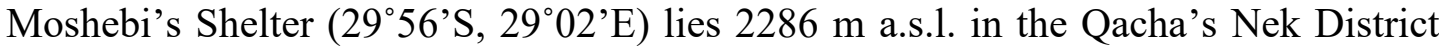
of southeastern Lesotho (Fig. 1). It is located some $10 \mathrm{~km}$ outside the Sehlabathebe National Park in a rock bluff that dominates the southwestern corner of the Sehlabathebe Basin and overlooks the point at which the Leqoa and Tsoelikane Rivers merge to form the Tsoelike, one of the principal tributaries of Lesotho's largest river, the Senqu (Orange) (Fig. 2). While the site is $\sim 80 \mathrm{~m}$ wide, it is nowhere more than $12 \mathrm{~m}$ deep behind the drip-line (Fig. 3). The space available for habitation $\left(\sim 160 \mathrm{~m}^{2}\right)$ is reduced by a substantial rock fall at the shelter's northern end, suggesting that the site was probably never occupied by a substantial number of people (Carter, 1969a: 18). Nevertheless, Moshebi's easterly orientation (facing the morning sun), its strategic position, and the fact that it offers "good protection from wind and snow" (Carter, 1978: 51) imply that it may have been frequently visited, perhaps encouraged by the seasonally active spring at its southern end. Twenty-eight groups of paintings across the site's rear wall that mostly depict people, eland, and other antelope were recorded during the 1969 field season (Carter, 1969a: 21-22).

Carter's (1969a, 1978) initial investigation uncovered a sequence of deposits extending $2.75 \mathrm{~m}$ below the modern surface, which he excavated in a series of 10 $\mathrm{cm}$-thick spits. Within this sequence the top $65 \mathrm{~cm}$ or so produced evidence of late Holocene occupation (Carter \& Vogel, 1974) within which Carter (1969a, 1978) distinguished two Later Stone Age industries. The more recent, from Spits 1-3, was distinguished from its predecessor in Spits $4-6$ by the presence of barbed and tanged 
pressure-flaked arrowheads, glass beads, and pottery. Below relatively thin layers of interstratified yellow sand and brown clay that contained virtually no artefacts the Moshebi's sequence continues with a deep succession of Middle Stone Age (MSA) assemblages. Carter (1969a) grouped these into two industries, the upper of which (in Spits 9-15) was distinguished from the lower (in Spits 16-29) by the presence of what he described as microburins along with large crescents, and micro-blade cores. Its blades were also considerably shorter than those of its predecessor industry, which was further differentiated by including backed blades, tanged blades, cylindrical blade cores, disc cores, and larger cores of Levallois type. Subsequent analysis (Carter, 1978) suggested a more complex MSA succession in which blade length varied from longer to shorter to longer again. Drawing this information together, Volman (1981) subsequently concluded that the Moshebi's MSA sequence samples pre-Howiesons Poort, Howiesons Poort, and post-Howiesons Poort occurrences. Though no radiocarbon or OSL dates are available for these assemblages, Moshebi's MSA succession is best paralleled at Melikane in the Senqu Valley, where preHowiesons Poort occupation reaches back to $\sim 80 \mathrm{ka}$ and the latest MSA occurrences fall $\sim 40 \mathrm{ka}$ (Stewart et al., 2012), with more recent ones occurring further north at Sehonghong (Loftus et al., 2015).

\subsection{Stratigraphy and taphonomy}

Both our fieldwork and that undertaken by Carter show that Moshebi's stratigraphy chiefly comprises a series of clays or sands mixed with angular rock fragments derived from weathering of the site's roof and walls, but with a significant anthropogenic element also present (Fig. 4, top). Of the nine layers that Carter (1969a) defined, the upper four are of Holocene age. Layer 1 comprises a fine, dusty horizon of LSA material mixed with twentieth-century items such as cartridge cases and Basotho pottery. Below this, Layer 2 was $30-65 \mathrm{~cm}$ thick with a fine, dusty texture that was black on initial exposure, but dark grey after drying out. Although no clearly defined hearths were recognised, this part of the deposit had a high ash content and yielded a substantial assemblage of LSA artefacts. Below it, Layers 3 and 4 consisted of a fine, clean yellow sand and a dark, orange-brown clay respectively, with some degree of inter-stratification evident between them. Carter (1978: 55) interpreted these layers as the result of increased spring activity within the site and noted that they were "to all intents and purpose[s] archaeologically sterile". Below, Layers 5-9 sampled Middle Stone Age occupations of Pleistocene date and did not preserve faunal material.

Our own work at Moshebi's revealed a more complex sequence (Fig. 4, bottom) than that reported by Carter (1969a, 1978). Following the system used by the Museum of London Archaeological Service (1994), we used differences in colour and texture to identify 26 separate archaeological contexts that we subdivided and excavated as successive $25 \mathrm{~mm}$-thick spits where necessary. After excavation we grouped these contexts into the following sequence of depositional phases (Fig. 5):

Phase 1: loose surface topsoil (Context 001) and the cut and fill of a natural water channel (Contexts 028 and 029), collectively equivalent to Carter's Layer 1;

Phase 2: a single context of dark grey-brown fine silty sand with considerable numbers of artefacts and other evidence of human activity (Context 002); 
Phase 3: a pit (Contexts 017 and 018) and post-hole (Contexts 010 and 011 ) that were the only features visible in our excavation. The post-hole measured $170 \mathrm{~mm}$ in maximum diameter and the same in maximum depth and included a vertically orientated packing stone. The pit itself reached a depth of $430 \mathrm{~mm}$ and measured 500 $\mathrm{mm}$ on its north-south axis and $400 \mathrm{~mm}$ on its east-west one. Both features lay below Context 002 and over Context 014. Note, however, that the post-hole was also cut into the top of Context 013, the uppermost fill of the underlying channel, while the pit was cut only from the top of Context 008 . As Context 013 was only found in a restricted area, the two features are shown at the same level in Fig. 5;

Phase 4: a natural water channel (Context 014) filled with a succession of dark grey brown to black fine sands and silts (Contexts 013, 008, 016, 015, 020). Many fragments of decayed sandstone were present in the Phase 4 deposits, some set into the deposit at a steep angle. We interpret this phase as evidence of relatively highenergy water flow through the site, followed by primarily aeolian infilling of the resulting channel;

Phase 5: another episode of relatively intense human occupation consisting of a dark grey/black silt (Context 012) above a second such silt with a small fine sand fraction (Context 019). Collectively, this Phase - along with Phases 2-4 - equates to Carter's (1969a) Layer 2. Faunal remains were best preserved in these upper phases, consistent with Carter's (1978: 55) observation that they were "numerous in the top 60 centimetres of the deposit [but] very infrequent in the lower layers";

Phase 6: the three contexts $(003,005,022)$ of this phase comprise fine to very fine yellow sand, probably resulting from relatively rapid episodes of aeolian deposition. They equate to Carter's (1969a) Layer 3;

Phase 7: a further natural water channel (Context 024) that was subsequently in-filled with dark yellow-brown fine to medium-grained sand (Contexts 023, 021);

Phase 8: another episode of aeolian deposition, possibly signalling drier conditions than those that followed it, marked by light orange/beige fine to very fine sand that was excavated in two contexts $(006,026)$. This phase and its successor equate to Carter's (1969a) Layer 4;

Phase 9: this phase's coarser brownish yellow sands (Contexts 004 and 025) may be the fills of yet earlier water channels lying above a reddish silty sand concretion with abundant stones (Context 007). It marks the transition to the Middle Stone Age (MSA) part of the Moshebi's sequence and equates to Carter's (1969a) Layer 5.

In addition to people digging at the site (Phase 3), at least two further agents have moved material through the Moshebi's deposits. First, water has clearly flowed through the excavation area on multiple occasions, particularly during Phases 7 and 4. This flow has been facilitated by the fact that the site's surface slopes markedly from south to north, and may — as Carter (1978: 55) suggested — partly reflect increased activity of the spring at the site's southern end under wetter climatic conditions. However, while our analysis suggests that some reworking of older sediments has taken place as a result (see below), very few artefacts or bones 
(Badenhorst et al., 2019) show evidence of water damage, perhaps because the site was only briefly flooded and rapidly scoured out rather than leaving artefacts and bones submerged for any length of time. This interpretation is supported by our observation during excavation that there was no sedimentary evidence for the pooling of water or formation of slackwater silts within the stratigraphy. A second way in which material may have moved between sedimentary units is via the rodent tunnels observed and excavated separately in Phases 2 (Context 009) and 5 (lower spits of Context 019) and by the relatively fresh nature of some of the bones recovered, including those of mole rats (Cryptomys hottentotus), vlei rats (Otomys sp.), and platannas (Xenopus laevis), as well as indeterminate insectivores and small rodents (Badenhorst et al., 2019).

\subsection{Dating}

Radiocarbon dates from Moshebi's Shelter are given in Table 1. Carter (1969a, 1978; Carter and Vogel, 1974) obtained two conventional dates on unidentified charcoal for the LSA assemblages. One - from relatively high up in Layer 2 (Spit 2) - places people there in the second half of the second millennium AD (260 $\pm 46 \mathrm{BP}, \mathrm{Pta}-314$, cal. AD 1505 to present), while the other, from close to its base (Spit 4), calibrates to the late first millennium BC $(2180 \pm 45$ BP, Pta-319, 356-40 cal. BC) (Table 1). While these dates are in correct sequence and consistent with the overall final LSA (post-classic Wilton; Lombard et al., 2012) nature of the artefacts recovered, those obtained from our own excavation are at variance with them. A determination from our Context 002 of $2200 \pm 25$ BP (UGAMS-11589, 357-113 cal. BC) is significantly older than that from Context 019 (940 \pm 25 BP, UGAMS-11591, cal. AD 1045-1214) below it, which is itself stratigraphically equivalent to the position of Carter's much older date Pta-319. This inversion is likely to be due to the taphonomic issues just discussed. Both determinations were run on unidentified charcoal.

A further AMS date on bone from Context 003 in Phase 6 toward the base of our excavation yielded a result of $4320 \pm 25$ BP (UGAMS-11590), which calibrates to 3010-2763 cal. BC at two sigma. However, the presence of Woodlot scrapers in this phase and in Phases 5 and 4 above it raises doubts about the accuracy of the date's associations since these scrapers are generally considered to be of early/midHolocene age (c. 9500-6000 BP; Mitchell and Arthur, 2014).

To gain additional information about the likely age of the Moshebi's deposits and their contents, Collis (2010) obtained OSL dates from sediment samples and potsherds recovered during the 2009 excavation (Table 2). Her results confirm the reworking of older sediments to which we have already drawn attention, as well as the downward movement of potsherds (and probably charcoal; UGAMS-11591) into Phase 5, which is stratigraphically equivalent to the lowest part of Carter's Layer 2. Based on the direct dating of five individual sherds, they also establish that people were present at the site early in the second millennium AD before the onset of the, Little Ice Age, consistent with similar dates elsewhere in highland Lesotho (Mitchell 1996a; Hobart, 2004; Collis, 2010). We return to the site's chronology and overall cultural sequence in the discussion section of our paper.

\section{Lithic assemblages}


The stone artefacts from Moshebi's were analysed following the approach developed by Deacon (1984), modified by experience of other sites in Lesotho (e.g. Mitchell, 1996a, 1996b; Mitchell et al., 2011). Our priority was to describe them in terms of broad patterns of raw material usage, core reduction, blank production, utilization, and the presence/absence of formally retouched tools in order to facilitate comparisons with other Maloti-Drakensberg LSA assemblages, rather than to engage in detailed morphometric studies or analysis of chaînes opératoires (cf. Pargeter, 2016). These patterns are presented here according to the Phases defined above. Since Phase 8 produced just seven artefacts we merge it with Phase 7.

\subsection{Raw material usage}

As elsewhere in highland Lesotho, people overwhelmingly preferred to use finegrained opalines (also known as crypto-crystalline silicas) when making stone tools (Table 3; Fig. 6). Except for hornfels, other rocks (notably quartz, quartzite, siltstone/mudstone, basaltic rocks, and sandstone) occur in only trace amounts. Hornfels begins in the same way, being absent from Phases 7 and 8 and accounting for only $0.5 \%$ of the artefacts in Phase 6 . Thereafter, however, it quickly gains in importance, making up $5.8 \%$ of the stone artefacts in Phase 5 and $10.3 \%$ of those from Phases 1-4. No information is available regarding the specific sources of the raw materials employed at Moshebi's, although opalines are likely to have come from a number of different outcrops given the variation in their colour, homogeneity, and grain, as well as possibly from nodules retrieved from rivers. Hornfels forms where shales have been metamorphosed by heat, for example along volcanic dykes, several of which outcrop in and close to the Sehlabathebe Basin. While we do not know from where the hornfels used in the more recent part of the Moshebi's LSA sequence came, the change in its usage relative to Phases 6-8 is sufficiently striking to suggest that it marks a shift in how people used the local landscape between the earlier and later phases of the site's LSA occupation.

\subsection{Core reduction and blank production}

Since stone is generally flaked before use, the types of cores produced and the kinds of blanks struck from them give initial insights into the reduction pathways followed (Table 4). Overall, it is clear that those camping at Moshebi's followed a largely expedient approach here since most cores fall into Deacon's (1984) irregular class and were used to produce flakes of a variety of sizes and shapes. We recognise, however, that the term 'irregular core' may mask important variability regarding the technological choices people made. There is little evidence of bipolar flaking, with just one clearly bipolar core identified (from Phase 2), along with a smattering of core-reduced pieces (Phases 2-6). Nor was much effort devoted to producing more specialized blade or bladelet blanks to judge from their rarity and the extreme scarceness of lames à crête (crested blades). Bladelet cores of one kind or another are nevertheless present in the assemblages recovered from Phases 4-7. While their absolute numbers are low, they show some tendency to be more common toward the base of the sequence, i.e. in Phases 6 (29\% of all cores) and 7/8 (25\% of all cores). Significantly, perhaps, four of the bladelet cores recovered were of the high-backed form, characteristic of, though not unique to, the late Pleistocene LSA Robberg Industry (Mitchell, 1995); three of these cores occur in Phase 6. 


\subsection{Utilization}

The vast majority of the usable flakes from our excavation show no macroscopically visible damage, suggesting that they were used, if at all, in tasks of relatively brief duration. What those were might be identified by microwear and organic residue analyses, but these have not been conducted on the Moshebi's assemblages, nor was magnification used during their study. In rare instances, however $(\mathrm{N}=40$; Table 4), some artefacts were clearly employed in a more sustained, intensive manner, sufficient to justify including them in Deacon's 'utilized' category. In most cases damage is relatively non-intrusive and confined to just one edge, but in a few instances it is more strongly evident and takes the form of clear notching or steep scar removal. One quartzite heavy edge-flaked piece (sensu Deacon 1984: 378) occurs in the Phase 7 assemblage.

\subsection{Formally retouched tools}

While 'utilized' artefacts are very few in number at Moshebi's, the 2009 excavation, like that of 1969 , did produce a substantial number of formal tools $(\mathrm{N}=532)$, i.e. flakes deliberately modified in size and shape to meet particular goals, or altered as a result of resharpening and mass reduction during their use for certain tasks (Table 4). Most of these artefacts are readily classifiable into one of the well-known formal tool classes widely recognised in the southern African Later Stone Age. Overall, formal artefacts comprise $2.5 \%$ of the flaked stone recovered from the 2009 excavation and show the widespread LSA pattern of emphasizing the use of the finest grained raw materials for their manufacture, even in assemblages, like those from Moshebi's, that are overwhelmingly made in these as a whole. Thus, just 19 of $398(4.8 \%)$ scrapers are made from hornfels and two $(0.5 \%)$ from siltstone/mudstone, with the remainder being made in opaline $(\mathrm{N}=377,94.7 \%)$. Adzes show a greater propensity for using non-opaline materials, with 11 (20.4\%, including one scraper-adze) made in hornfels and two in siltstone/mudstone (3.7\%) out of a total of 54 artefacts, but all the backed microliths and bifacial elements found are made in opaline alone.

Formal tools are more common in the upper part of the Moshebi's sequence, accounting for $2.7 \%$ of all the flaked stone artefacts in Phases 1-5 compared to just $1.1 \%$ in Phases 6-8. Individual classes of formal tool also exhibit a degree of temporal patterning as we now discuss (Fig. 7).

Scrapers are overwhelmingly the most common kind of formal tool at Moshebi's, accounting for almost three-quarters $(74.8 \%, \mathrm{~N}=398)$ of the total (Table 4; Fig. 8). Additionally, one artefact from Phase 4 was classified as a core-scraper, while another from Phase 2 showed signs of having been used as both a scraper and as an adze. Scrapers have a convex working edge, and microwear, residue, and experimental studies elsewhere in southern Africa suggest that their primary use was in cleaning animal hides (Deacon, 1984). They account for the largest number of formally retouched artefacts in all phases save Phase 7, where they come second after miscellaneous retouched pieces, i.e. retouched artefacts that resist easy classification into any specific class. Almost all of the scrapers found at Moshebi's are made on flakes and in some instances $(\mathrm{N}=41,10.3 \%)$ the bulb of percussion has been removed, presumably to facilitate hafting. Very few scrapers $(\mathrm{N}=9,2.3 \%)$ are backed, i.e. their distal ends have been blunted by steep, abrupt retouch in a way that 
suggests it was done to facilitate hafting (Deacon, 1984: 388). Unusually, two (from Context 015) are retouched at their proximal, rather than distal, ends, while another (from Context 019) is retouched on its ventral, instead of its dorsal, surface.

Several scrapers are of the Woodlot type (Fig 8: 3) first recognised in Lesotho at an open-air site sampled during contract archaeology operations along the Southern Perimeter Road (Parkington et al., 1987; Mitchell et al., 1994). Woodlot scrapers are elongated end-scrapers that have a steep, convex, primary working edge typically placed directly opposite the bulb of percussion (although this may sometimes be removed or not be present in the first place where a struck flake was not used as the blank for making the artefact). They typically taper from working edge to butt and feature steep, layered, step-terminated retouch along one, or more commonly both, of the artefact's lateral margins. This latter form of retouch has previously been referred to as 'adze-like' (e.g. Mitchell, 1996b), and Opperman (1987) suggested that it was designed to facilitate hafting in an end-mounted fashion, i.e. parallel to the handle itself, while smaller, thumbnail-shaped scrapers dating to the middle Holocene were presumed to have been hafted differently. Bousman (2005), on the other hand, argued that Woodlot scrapers were dual-function tools, able to work both skins (at the distal, convex end) and wood (using the lateral margins). Morphometric analysis of a large sample of Woodlot scrapers from Ntloana Tšoana in western Lesotho strongly supports Opperman's interpretation that these tools were indeed end-mounted. Microwear studies on the same assemblage combined with detailed analysis of their depositional context further indicate that hide-working was their primary association (Arthur, 2018). Similar artefacts have been described as 'duckbill scrapers' elsewhere in southern Africa, particularly in the Fynbos and Forest Biomes of the Cape (Goodwin and van Riet Lowe, 1929; Deacon, 1984). In the Maloti-Drakensberg they appear quite rapidly c. 9500-9300 BP and are largely confined to the early Holocene, continuing on to $c$. $7000 \mathrm{BP}$ in eastern and western Lesotho (Mitchell, 1996b; Arthur et al., 2018) and c. $6000 \mathrm{BP}$ on the South African side of the Caledon River (Wadley, 2000). Within the Moshebi's sequence, scrapers that show layered and steep retouch along either one or both lateral margins are almost entirely restricted to Phase $4(\mathrm{~N}=$ $35)$ - the sediments of which are the fills of a natural water channel presumably deposited from elsewhere within the site - as well as Phases $5(\mathrm{~N}=16)$, and $6(\mathrm{~N}=$ 1). Just a few examples occur higher up in the sequence in Phases $1(\mathrm{~N}=1)$ and $2(\mathrm{~N}$ =4). Metric data also show that Woodlot scrapers are longer and thicker than the others at the site (Table 5).

Adzes (Fig. 8) are the second most common retouched tool class at Moshebi's, accounting for just over $10 \%$ of all formal artefacts. Experimental work and microwear studies suggest that they were predominantly used to work wood, though sometimes also bone (Binneman and Deacon, 1986). Except for two examples from Phase 7, adzes are restricted to Phases 1-5. They are most common toward the very end of the Moshebi's sequence in Phases $1-2(\mathrm{~N}=29,17.9 \%$ of all formal tools, compared to $\mathrm{N}=26,7.7 \%$, in Phases 4-5).

Backed microliths (Fig. 9) are relatively few in number, a pattern previously noted at Sehonghong, where it was suggested that the use of bone points and possibly iron obtained via exchange with Farming Communities living below the uKhahlambaDrakensberg Escarpment might explain it, given that these artefacts' primary function was probably to arm arrows (Mitchell, 1996a). Although segments are more 
numerous in Phases 4 and 5 (Table 4; Fig. 9: 5-6) than later on in the sequence, the numbers involved are few. We are thus reluctant to read this as further evidence for reworking of older sediments dating to the mid-Holocene, when segments were particularly common in southern Africa (Lombard et al., 2012), not least because they also occur at low frequency in assemblages of late Holocene age (e.g. Mitchell, 1996a). Apart from segments, backed bladelets - retouched along either one or both lateral edges — and backed flakes are also represented, along with a single borer (from Phase 5; Fig. 9: 2).

Carter (1969a, 1978) found several bifacially pressure-flaked artefacts in his excavations at Moshebi's, including both pressure-flaked backed microliths and barbed and tanged arrows. Our excavations produced just one example of the former (in Context 001), for which good dates in the order of c. 2100-1700 BP are now available from Likoaeng in the Senqu Valley (Mitchell et al., 2011) and Collingham Shelter below the Escarpment in KwaZulu-Natal (Mazel, 1992a), with older examples known at Blydefontein in the Karoo (Bousman, 1991) and undated instances present at Leqhetsoana in the Caledon Valley (Mitchell et al., 1994). However, we did recover four fragments of bifacial projectile points, three from Phase 4 (Fig. 9: 7) and one from Phase 2. Elsewhere, these artefacts occur mostly as surface finds, but excavations at Rose Cottage Cave (Wadley, 2000) and Blydefontein (Bousman, 1991) in central South Africa suggest that they date to within the last 2200 years. Like pressure-flaked backed microliths, the distribution of which they overlap and almost entirely encompass, they may have helped to define a large, perhaps ethnolinguistically recognisable, alliance network covering Lesotho and adjacent parts of the South African interior (Mitchell, 1999).

Miscellaneous retouched pieces comprise the remainder of the formal tool assemblage. They differ from the utilized artefact category in displaying sufficient evidence of modification to suggest that this is deliberate, rather than simply a result of use. Except in the very small $(\mathrm{N}=11)$ assemblage from Phase 7 (where they make up $63.6 \%$ of the formal tools present, $\mathrm{N}=7$ ) nowhere do they comprise a large fraction of the retouched artefacts recovered.

\subsection{Ground stone}

Only a few ground stone items are present. They include two possible palette fragments, one in sandstone from Phase 7, the other in shale from Phase 2. Phase 2 also produced a possible hammerstone, with a more definite example coming from Phase 4, along with a further possible fragment from there and another from Phase 5. The Phase 4 inventory also includes three grindstone fragments, plus four apparently unworked cobble fragments; all are in basaltic rock.

\section{Non-lithic assemblages}

\subsection{Pottery}

Pottery is a standard feature of late Holocene LSA assemblages in highland Lesotho and Moshebi's is no exception. The 2009 excavation produced a total of 34 sherds, none larger than $42 \mathrm{~mm}$ in maximum dimension and several of them no more than crumbs (Table 6). Most $(\mathrm{N}=26)$ were recovered from Contexts 001 and 002, i.e. at 
the very top of the sequence, though three came from Context 015 (Phase 4), three from Context 012 (Phase 5), and two more from Context 019 (also Phase 5). As explained above, the sherds from Phases 4 and 5 are certainly intrusive into the sediments in which they were found. The OSL dates obtained on some of them, as well as on two sherds from Context 002 (Table 3), hint that much - perhaps even all - of the pottery found at Moshebi's is of early second-millennium AD date.

All but three sherds are very dark grey in colour (Munsell 10YR 3/1.5 or 10YR 3/1). The exceptions are dark reddish brown (Munsell 5YR 5/2) and are probably of recent Basotho manufacture, consistent with their presence in the uppermost spit of Context 001. The dark grey appearance of the other sherds, on the other hand, their uniformly grit temper, their relatively thin walls (mean $=7.0 \pm 1.3 \mathrm{~mm}, \mathrm{~N}=16$ ), and their lack of decoration assign them to a tradition of hunter-gatherer-produced ceramics that is well-attested in the Maloti-Drakensberg Mountains, from the upper Thukela Basin in the north to the Maclear/Barkly East area in the south and including all of highland Lesotho (Opperman, 1987; Mazel, 1992b; Mitchell et al., 1994, 2011; Mitchell, 1996a). The small and highly fragmented nature of the Moshebi's ceramic assemblage is also typical of the region.

\subsection{Worked bone and ostrich eggshell}

We found a few $(\mathrm{N}=9)$ fragmentary bone tools, along with eleven polished bone flakes or fragments (Badenhorst et al., 2019: Table 7). Those that are identifiable are either points or linkshafts, but could not be assigned with certainty to one category or the other except for a polished, rounded piece from Context 008 (Phase 4) the tapering of which suggests that it may have been a point. None of the worked bone fragments found exceeds $35 \mathrm{~mm}$ in length and most $(\mathrm{N}=15)$ are $\leq 20 \mathrm{~mm}$ long.

We found no ostrich eggshell or ostrich eggshell beads, although Carter's (1969b) unpublished field notes make reference to two such beads from his original excavation, which also produced a much larger contingent of bone tools, including four complete points (Carter, 1969a: 15). Ostrich eggshell is extremely rare in highland Lesotho, where ostriches were probably never present, and beads are only common at Sehonghong, most likely introduced from the Free State/Karoo plains of the southern African interior (Mitchell, 1996c; Stewart et al., 2020).

\subsection{Glass}

A small number of glass fragments were recovered from Contexts $001(\mathrm{~N}=15)$ and $002(\mathrm{~N}=15)$, both at the top of the LSA deposits, although unlike Carter (1969a: 14), we recovered no examples of glass beads. Most of the glass fragments were clear, but examples of brown, green, blue, and black glass were also present; all likely come from bottles. Three glass flakes from Context 002 Spit 1 at the very top of the Phase 2 sediments appear to have been deliberately retouched, matching an observation made by Carter (1969a: 14). Glass fragments with modified edges are rare in the southern African record and can be readily produced by accident (Beaumont, 1961), but Bushman communities survived in highland Lesotho until the end of the nineteenth century, retaining knowledge of how to make stone tools (Vinnicombe, 1976, 2009). Other instances are known of bottle glass being recycled as a lithic raw 
material at broadly the same time (e.g. Saitowitz and Sampson, 1992; Chazan et al., 2013) and Frere (1881) reports the practice from nineteenth-century Namibia.

\subsection{Other finds}

Eleven small fragments of metal (iron or steel) were found in Contexts 001 and 002, along with one gimlet and a nail, probably left on-site after the 1969 excavation. A broken plastic button was also recovered from Context 001 .

\section{Discussion}

As a result of our re-excavation it is now clear that the LSA sequence at Moshebi's - at least in the site's central area, but perhaps throughout it - has been affected by the vertical movement of material culture and fragments of charcoal by animal agents (Badenhorst et al., 2019) and the repeated flow of water (the channels identified as Contexts 029 (Phase 1), 014 (Phase 4), and 024 (Phase 7) and their fills). The effects of this are most evident in the stratigraphic inconsistencies between our radiocarbon dates and those obtained by Carter (Carter and Vogel, 1974) and between them and the OSL ages obtained by Collis (2010). However, they are almost certainly further signalled by the presence of Woodlot scrapers - a characteristically early/midHolocene (c. 9500-6000 BP) tool form — in contexts that also produced pottery (Contexts 015 and 019) and fragments of bifacial arrows (Context 008), items with impeccable late Holocene $(\leq 2200 \mathrm{BP})$ associations.

We do not, however, consider our re-excavation of the site to be a disappointment, even if it did not deliver the finely resolved stratigraphy or finds indicative of contact with Farming Communities (diagnostic pottery, glass beads, metal, evidence of domesticated animals or plants) for which we had hoped. Instead, Moshebi's emphasizes how challenging some rockshelter sequences can be. To meet this challenge requires detailed excavation, involving the maximum possible stratigraphic control and careful attention to taphonomic processes, particularly how sediments have built up and subsequently been altered. Recent studies elsewhere in Lesotho, including at Melikane (Stewart et al., 2012) and Ntloana Tšoana (Arthur, 2018; Morley et al., in prep.), confirm the value of this approach, which overcomes a strong disciplinary tendency to classifying sites into two kinds: problematic palimpsests or high-resolution sequences. Rather than maintain this unhelpful dichotomy, we need to become better at working with the reality that all sites lie somewhere between these two poles.

What, then, can Moshebi's Shelter tell us?

Firstly, the application of OSL dating to some of the potsherds found proved particularly useful. Highly consistent among themselves, all six of the dates secured fall within the early second millennium AD, just like four sherds from Melikane and six out of nine dated at Sehonghong (Collis, 2010). OSL dates previously obtained on pottery at Pitsaneng, just $1 \mathrm{~km}$ from Sehonghong, concur (Hobart, 2004). Together with the available radiocarbon dates, these results point to the Lesotho highlands having been particularly attractive to people during the warmer, drier conditions of the Medieval Climatic Anomaly, c. AD 550-1300 (Stewart and Mitchell, 2018a). This is in sharp contrast to the northern KwaZulu-Natal uKhahlamba-Drakensberg, 
which seems to have been completely abandoned during this interval, perhaps because local hunter-gatherers moved downslope to benefit from access to metal, grain, and other desirables via exchange with Farming Communities in the central Thukela Basin (Mazel, 2009). Significantly, however, analysis of organic residues on pottery from Sehonghong and Likoaeng, including directly obtained radiocarbon dates, shows that at least some of those inhabiting highland Lesotho at this time kept and exploited domestic livestock as a source of food (Fewlass et al., 2020; cf. Mitchell et al., 2008, 2011; Horsburgh et al., 2016). We do not know whether this included those living at Moshebi's since neither Carter's (1969a, 1978) excavations nor ours (Badenhorst et al., 2019) produced identifications of domestic sheep or cattle.

Secondly, our work confirms Carter's (1969a, 1978) conclusion that the site preserves evidence of occupation within the last 2000 years or so by people who made what is now termed a post-classic Wilton (or final LSA) toolkit. Finds such as bottle glass flakes (from both excavations) or a mid-nineteenth-century musket ball (Carter, 1969a: 16) undoubtedly confirm that occupation continued into historic times, perhaps by individuals associated with the creolized AmaTola 'Bushmen' discussed by Challis $(2012,2014)$, who are known to have lived in this area of Lesotho at that time. However, in our view the vertical movement of material that we have detected and - we would add - Carter's spit-based excavation techniques does not provide a sound basis for differentiating Phases 1-5 into two distinct, readily recognisable industries, one characterized by pottery, bifacial arrows, and items of ultimately non-African origin, and the other not. We do not exclude the possibility that a pre-ceramic expression of the final LSA is present at Moshebi's (most likely in our Phase 5, from which bifacial artefacts were absent and in which only five, clearly intrusive, small sherds were found), but argue that this cannot be satisfactorily demonstrated due to the taphonomic issues that we have described.

Thirdly, our excavation renders the Moshebi's LSA sequence more complex than the simple bipartite division that Carter inferred. Two sets of observations lead us to this conclusion. In the first place we draw attention again to the presence among the 271 scrapers from Phases 4 and 5 of 51 of the Woodlot type otherwise dated in Lesotho to the early/mid-Holocene, c. 9500-6000 BP (e.g. Mitchell and Arthur, 2014). These scrapers are also notably longer and thicker than the others present in the same contexts (Table 5). Although none are obviously rolled or show other evidence of water damage, we suggest that they either reflect the reworking of older sediments elsewhere in the site during the formation of the Phase 4 deposits and/or the accumulation of the Phase 4 and 5 sediments over a long period of time that spanned both the first half of the Holocene and more recent times. Either way, we take the presence of these scrapers to signal that people also occupied Moshebi's at one or more times between broadly 9500 and 7000/6000 BP. Sehonghong to the west (Mitchell, 1996b) and Good Hope Shelter to the east and below the summit of the uKhahlamba-Drakensberg Escarpment (Cable et al., 1980), as well as Belleview just outside the Sehlabathebe Basin itself (Carter and Vogel, 1974; Carter, 1978), all provide geographically close comparisons at this time.

The other indicator of a more complex site history comes from the several highbacked bladelet cores found in Phase 6. As we have noted, these artefacts are most typical of late Pleistocene Robberg assemblages, and bladelet cores as a whole, as 
well as bladelets, are also more common in the lower part of our sequence (Phases 68; Table 4). The same characteristics are evident in the material from Carter's stratigraphically equivalent Layers 3 and 4 now housed in the University of Cambridge's Museum of Archaeology and Anthropology (Carter et al., 1988: 196), though in both cases absolute numbers of artefacts are few. It would not, however, be surprising if makers of Robberg stone tools had used Moshebi's before and/or after the Last Glacial Maximum. They certainly lived at these times in Sehonghong $40 \mathrm{~km}$ further west (Mitchell, 1995; Pargeter et al., 2017), where a vervet monkey (Chlorocebus pygerythrus) scapula and a few shell beads (Nassarius kraussianus; Nerita sp.; Trachycardium sp.) document Pleistocene contacts between the Senqu Valley and the Indian Ocean coast (Plug and Mitchell, 2008), contacts that could easily have passed via the Sehlabathebe Basin.

Fourthly and finally, we want to stress that our identification of ancient water channels within the site's stratigraphy must also have been a reality for those who once lived inside it. Often overlooked, this point is significant since the changing physical circumstances of any given rockshelter alter the possibilities that it offers to potential human residents. Sediments build up inside it, blocks of stone fall from the roof, graves, pits, and other features are dug into existing layers, non-human agents, such as water, rework the site's surface, and people develop and may long retain memories of how and when it was used and what activities were undertaken where (Arthur, 2018). Collectively, these processes relate to the distinction drawn by Parkington $(1980,1988)$ and Binford (1982) between a site's physical location and its 'place', i.e. the set of opportunities that it offers for living there, opportunities that unlike its geographical co-ordinates - change as the environment around it evolves. Given how much a rockshelter's physical form can change over time, place, and the potentiality that it entails, must always have been as much about how life unfurled inside its dripline and below its roof as about how those living there engaged with the wider landscape beyond (Bailey \& Galanidou, 2009; Arthur, 2018). As Carter (1969a, 1970, 1978) realised, Moshebi's small size, large area of rock fall, and potentially wet conditions are as much a part of its history as the attractions of its spring, its commanding view, and its position within wider ecological and social systems that certainly encompassed the Sehlabathebe Basin, but may well also - at times - have extended downslope into the Midlands of KwaZulu-Natal or west to the Senqu River.

\section{Conclusion}

Fifty years on, our re-excavation and re-analysis of Moshebi's has reinforced the case for highland Lesotho having experienced a complex history of successive pulses of occupation by Later Stone Age hunter-gatherers. Moshebi's was not just used during the late Holocene, but probably also by makers of at least two earlier LSA toolkits, as well as intensively during the early second millennium AD. These pulses almost certainly reflect the availability of key resources such as plant foods, game, freshwater, firewood, natural shelter, and toolstone relative to their occurrence in neighbouring regions, especially South Africa's semi-arid interior (Stewart et al., 2016; Stewart and Mitchell, 2018a, 2018b), contact with which is indicated at Moshebi's by rare pressure-flaked arrows, pressure-flaked backed microliths, and ostrich eggshell beads. Future work in highland Lesotho must, however, now step beyond Pat Carter's shadow to address a wider variety of sites, not just the most 
obvious, large, deep-sequence sites whose investigation he pioneered. As he pointed out fifty years ago when first reporting his fieldwork at Moshebi's Shelter (Carter, 1969a), in the Sehlabathebe Basin alone numerous rockshelters and open-air sites still await a new generation of researchers.

\section{Funding sources}

Excavations at Moshebi's Shelter were funded by the Boise Fund of the University of Oxford in the form of a grant awarded to Capelli and Mitchell.

\section{Acknowledgments}

We are grateful to the Department of Culture of the Kingdom of Lesotho for granting permission for our fieldwork at Moshebi's Shelter and for permitting finds to be exported for analysis. We also thank Morena Phiri-ea-Tlala Mohale and the people of Ha Moshebi for permission to work at the site. The excavation greatly benefitted from the intellectual (and physical!) input of Teboho Mokotjo, Rethabile Mokhachane and Ntiti Thene. Sam Challis kindly allowed us to use his photograph of Moshebi's Shelter, while Sam Lunn-Rockliffe produced Figures 1 and 3. Finally, we also thank the editors of this special issue for their invitation to contribute to it and the referees whose comments improved our original draft.

\section{References}

Arthur, C., 2018. The Social World of Hunter-Gatherers in Early Holocene Lesotho: Integrating Method and Theory. D.Phil. Dissertation, Archaeology, University of Oxford, Oxford.

Arthur, C., Mitchell, P.J., Dewar, G.I., Badenhorst, S., 2018. After the silt: middle and late Holocene hunter-gatherer archaeology of the Metolong Dam, Lesotho. S.Afr. Hum. 31, 129-179.

Badenhorst, S., Mitchell, P.J., Arthur, C., Capelli, C., 2019. Late Holocene fauna from Moshebi's Shelter, a Later Stone Age site in Lesotho. S. Afr. Hum. 32, 83-107.

Bailey, G.N., Galanidou, N. 2009. Caves, palimpsests and dwelling spaces: examples from the Upper Palaeolithic of south-east Europe. World Archaeol. 41, 215-241.

Beaumont, P.B., 1961. The problem of glass implements. Bull. S. Afr. Mus. Assoc. 7(8), 161-163.

Binford, L.R., 1982. The archaeology of place. J. Anthropol. Archaeol. 1, 5-31.

Binneman, J.N.F., Deacon, J., 1986. Experimental determination of use wear on stone adzes from Boomplaas Cave, South Africa. J. Archaeol. Sci. 13, 219-228.

Bousman, C.B., 1991. Holocene Paleocology and Later Stone Age Hunter-Gatherer Adaptations in the South African Interior Plateau. Ph.D. Dissertation. Anthropology, Southern Methodist University, Dallas. 
Bousman, C.B., 2005. Coping with risk: Later Stone Age technological strategies at Blydefontein Rock Shelter, South Africa. J. Anthropol. Archaeol. 24, 193-226.

Cable, J.H.C., Scott, K., Carter, P.L., 1980. Excavations at Good Hope Shelter, Underberg District, Natal. Ann. Natal Mus. 24(1), 1-34.

Carter, P.L., 1969a. Moshebi's Shelter: excavation and exploitation in eastern Lesotho. Lesotho Notes and Records 8, 1-11.

Carter, P.L., 1969b. Moshebi's Shelter. Unpublished field notebook on file at the University Museum of Archaeology and Anthropology, University of Cambridge, Cambridge.

Carter, P.L., 1970. Late Stone Age exploitation patterns in southern Natal. S. Afr. Archaeol. Bull. 25, 55-58.

Carter, P.L., 1976. The effects of climatic change on settlement patterns in eastern Lesotho during the Middle and Later Stone Ages. World Archaeol. 8, 197-206.

Carter, P.L., 1978. The Prehistory of Eastern Lesotho. Ph.D. Dissertation. Archaeology, University of Cambridge, Cambridge.

Carter, P.L., Mitchell, P.J., Vinnicombe, P.V., 1988. Sehonghong: The Middle and Later Stone Age Industrial Sequence at a Lesotho Rock-Shelter. British Archaeological Reports, Oxford.

Carter, P.L., Vogel, J.C., 1974. The dating of industrial assemblages from stratified sites in eastern Lesotho. Man 9, 557-570.

Challis, S., 2012. Creolisation on the nineteenth-century frontiers of southern Africa: a case study of the AmaTola 'Bushmen' in the Maloti-Drakensberg. J. S. Afr. Stud. $38,265-280$.

Challis, S., 2014. Binding beliefs: the creolisation process in a 'Bushman' raider group in nineteenth-century southern Africa. In: Deacon, J., Skotnes, P. (Eds.), The Courage of //Kabbo: Celebrating the 110th Anniversary of the Publication of Specimens of Bushman Folklore. University of Cape Town Press, Cape Town, pp. 247-264.

Chazan, M., Porat, N., Sumner, T.A., Horwitz, L.K., 2013. The use of OSL dating in unstructured sands: the archaeology and chronology of the Hutton Sands at Canteen Kopje (Northern Cape Province, South Africa). Archaeol. Anthropol. Sci. 5, 351363.

Collis, B., 2010. Dating the Introduction of Pottery to the Maloti-Drakensberg Region of Southern Africa Using Optically Stimulated Luminescence. B.A. (Hons) Dissertation. Archaeology and Anthropology, University of Oxford, Oxford.

Deacon, J., 1984. The Later Stone Age of Southernmost Africa. British Archaeological Reports, Oxford. 
Fewlass, H., Mitchell, P.J., Casanova, E., Cramp, L.J.E., 2020. Of milk and men: direct chemical evidence of dairying by hunter-gatherers in the highlands of Lesotho in the late first millennium AD. Nature Human Behaviour

Frere, B. 1881. Relations between civilised and savage life. J. Anthropol. Inst. 11, 313-352.

González-Santos, M., Montinaro, F., Oosthuizen, O., Oosthuizen, E., Busby, G.B.J., Anagnostou, P., Destro-Bisol, G., Pascali, V., Capelli, C., 2015. Genome-wide SNP analysis of southern African populations provides new insights into the dispersal of Bantu-speaking groups. Genome Biol. Evol. 7, 2560-2568.

Goodwin, A.J.H., van Riet Lowe, C., 1929. The Stone Age cultures of South Africa. Ann. S. Afr. Mus. 27, 1-289.

Hobart, J.H., 2004. Pitsaneng: evidence for a neolithic Lesotho? Before Farming 2, 261-270.

Horsburgh, K.A., Moreno-Mayar, J.V., Gosling, A.L. 2016. Revisiting the Kalahari debate in the highlands: ancient DNA provides new faunal identifications at Sehonghong, Lesotho. Azania: Archaeol. Res. in Africa 51, 295-306.

Loftus, E., Stewart, B.A., Dewar, G.I., Lee-Thorp, J.A., 2015. Stable isotope evidence of late MIS3 to middle Holocene palaeoenvironments from Sehonghong Rockshelter, eastern Lesotho. J. Quat. Sci. 30, 805-186.

Lombard, M., Wadley, L., Deacon, J., Wurz, S., Parsons, I., Mohapi, M., Swart, J., Mitchell, P.J., 2012. South Africa and Lesotho Stone Age sequence updated (I). S. Afr. Archaeol. Bull. 67, 123-144.

Marks, S.J., Levy, H., Martinez-Cadenas, C., Montinaro, F., Capelli, C., 2012. Migration distance rather than migration rate explains genetic diversity in human patrilocal groups. Mol. Ecol. 21, 4958-4969.

Marks, S.J., Montinaro, F., Levy, H., Brisighelli, F., Ferri, G., Bertoncini, S., Batini, C., Busby, G.B.J., Arthur, C., Mitchell, P.J., Stewart, B.A., Ooosthuizen, O., Oosthuizen, E., d'Amato, M.E., Davison, S., Pascali, V., Capelli, C., 2015. Static and moving frontiers: the genetic landscape of southern African Bantu-speaking populations. Mol. Biol. Evol. 32, 29-43.

Mazel, A.D., 1992a. Collingham Shelter: the excavation of late Holocene deposits, Natal, South Africa. Natal Mus. J. Hum. 4, 1-51.

Mazel, A.D., 1992b. Early pottery from the eastern part of southern Africa. S. Afr. Archaeol. Bull. 47, 3-7.

Mitchell, P.J., 1995. Revisiting the Robberg: new results and a revision of old ideas at Sehonghong rock-shelter, Lesotho. S. Afr. Archaeol. Bull. 50, 28-38. 
Mitchell, P.J., 1996a. Sehonghong: the late Holocene assemblages with pottery. S. Afr. Archaeol. Bull. 51, 17-25.

Mitchell, P.J., 1996b. Filling the gap: the early and middle Holocene assemblages from new excavations at Sehonghong Rock Shelter, Lesotho. S. Afr. Field Archaeol. $5,17-27$.

Mitchell, P.J., 1996c. Prehistoric exchange and interaction in southeastern southern Africa: marine shells and ostrich eggshell. Afr. Archaeol. Rev. 13, 35-76.

Mitchell, P.J., 1999. Pressure-flaked points in Lesotho: dating, distribution and diversity. S. Afr. Archaeol. Bull. 54, 90-96.

Mitchell, P.J., Arthur, C., 2014. Ha Makotoko: Later Stone Age occupation across the Pleistocene/Holocene transition in western Lesotho. J. Afr. Archaeol. 12, 205-232.

Mitchell, P.J., Parkington, J.E., Yates, R., 1994. Recent Holocene archaeology in western and southern Lesotho. S. Afr. Archaeol. Bull. 49, 27-56.

Mitchell, P.J., Plug, I., Bailey, G.N., Charles, R.L.C., Esterhuysen, A.B., Lee-Thorp, J.A., Parker, A.G., Woodborne, S., 2011. Beyond the drip-line: a high-resolution open-air Holocene hunter-gatherer sequence from highland Lesotho. Antiquity 85, $1225-1242$.

Mitchell, P.J., Plug, I., Bailey, G.N., Woodborne, S., 2008. Bringing the Kalahari debate to the mountains: late first millennium $\mathrm{AD}$ hunter-gatherer/farmer interaction in highland Lesotho. Before Farming 3, 1-22.

Montinaro, F., Davies, J., Capelli, C. 2016. Group membership, geography and shared ancestry: genetic variation in the Basotho of Lesotho. Am. J. Phys. Anthropol. $160,156-161$.

Museum of London Archaeological Service, 1994. The MoLAS Archaeological Site Manual. Museum of London Archaeological Service, London.

Naroll, R.S., 1962. Floor area and settlement population. Am. Antiquity 27, 587-589.

Opperman, H., 1987. Later Stone Age Hunters and Gatherers of the Southern Drakensberg Range and its Foothills. British Archaeological Reports, Oxford.

Pargeter, J., 2016. Lithic miniaturization in late Pleistocene southern Africa. J. Archaeol. Sci.: Reports 10, 221-236.

Pargeter, J., Loftus, E., Mitchell, P.J., 2017. New ages from Sehonghong rock shelter: implications for the late Pleistocene occupation of highland Lesotho. J. Archaeol. Sci.: Reports 12, 307-315.

Parkington, J.E., 1980. Time and place: some observations on spatial and temporal patterning in the Later Stone Age sequence in southern Africa. S. Afr. Archaeol. Bull. 35, 73-112. 
Parkington, J.E., 1988. The Pleistocene/Holocene transition in the western Cape: observations from Verlorenvlei. In: Bower, J., Lubell, D. (Eds.), Prehistoric Cultures and Environments in the Late Quaternary of Africa. British Archaeological Reports, Oxford, pp. 197-206.

Parkington, J.E., Poggenpoel, C.A., Yates, R., 1987. Lesotho Rescue Archaeology 1982/83. University of Cape Town Department of Archaeology, Cape Town.

Plug, I., Mitchell, P.J., 2008. Sehonghong: hunter-gatherer utilization of animal resources in the highlands of Lesotho. Ann. Transvaal Mus. 45, 31-53.

Saitowitz, L., Sampson, C.G., 1992. Glass trade beads from rock shelters in the Upper Karoo. S. Afr. Archaeol. Bull. 47, 94-103.

Stewart, B.A., Dewar, G.I., Morley, M.W., Inglis, R.H., Wheeler, M., Jacobs, Z., Roberts, R.G., 2012. Afromontane foragers of the Late Pleistocene: site formation, chronology and occupational pulsing at Melikane Rockshelter, Lesotho. Quat. Int. $270,40-60$.

Stewart, B.A., Parker, A.G., Dewar, G.I., Morley, M.W., Allott, L.F., 2016. Follow the Senqu: Maloti-Drakensberg paleoenvironments and implications for early human dispersals into mountain systems. In: Jones, S.C., Stewart, B.A. (Eds.), Africa from MIS6-2: Population Dynamics and Paleoenvironments. Springer, Dordrecht, pp. $247-271$.

Stewart, B.A., Mitchell, P.J., 2018a. Late Quaternary palaeoclimates and humanenvironment dynamics of the Maloti-Drakensberg region, southern Africa. Quat. Sci. Rev. 196, 1-20.

Stewart, B.A., Mitchell, P.J., 2018b. Beyond the shadow of a desert: aquatic resource intensification on the roof of southern Africa. In: Lemke, A. (Ed.), Foraging in the Past: Archaeological Studies of Hunter-Gatherer Diversity. University of Colorado Press, Boulder, pp. 159-208.

Stewart, B.A., Zhao, Y., Mitchell, P.J., Dewar, G.I., Gleason, J.D., Blum, J.D. 2020. Ostrich eggshell bead strontium isotopes reveal persistent macroscale social networking across late Quaternary southern Africa. Proc. Nat. Acad. Sci. (USA) doi/10.1073/pnas.1921037117

Vinnicombe, P.V., 1976. People of the Eland. University of Natal Press, Pietermaritzburg.

Vinnicombe, P.V., 2009. Basotho oral knowledge. In: Mitchell, P.J., Smith, B.W. (Eds.), The Eland's People: New Perspectives in the Rock Art of the MalotiDrakensberg Bushmen. Essays in Memory of Patricia Vinnicombe. Wits University Press, Johannesburg, pp. 165-190.

Volman, T.P., 1981. The Middle Stone Age in the Southern Cape. Ph.D. Dissertation. Anthropology, University of Chicago, Chicago. 
Wadley, L., 2000. The Wilton and pre-ceramic post-classic Wilton industries at Rose Cottage Cave and their context in the South African sequence. S. Afr. Archaeol. Bull. 55, 90-106. 